


\title{
Hélio Jaguaribe, pensamento sócio-político brasileiro e desenvolvimento: entre textos, contextos e intelectuais ${ }^{1}$
}

\author{
Hélio Jaguaribe, Brazilian Sociopolitical \\ Thinking and Development: between texts, \\ contexts and intellectuals
}

\author{
Alessandro Leme*
}

\begin{abstract}
Resumo
Neste artigo vamos dar ênfase a obra de Hélio Jaguaribe a partir de um triplo movimento que envolve uma breve caracterização biográfica do autor, um segundo, evidenciando a influência do autor para o pensamento sócio-político brasileiro por meio de como a obra do autor foi mobilizada como objeto de investigação e, em terceiro, problematizar importância e tratamento que o autor realizou em prol de uma compreensão dos problemas acerca do Estado e do desenvolvimento econômico brasileiro.
\end{abstract}

Palavras-chave: Desenvolvimento; Pensamento sócio-político brasileiro; Hélio Jaguaribe.

\begin{abstract}
In this article we are going to emphasize the work of Hélio Jaguaribe from a triple movement that involves a brief biographical characterization of the author, a second, showing the influence of the author for Brazilian socio-political thought through how the author's work was mobilized as an object of investigation and, thirdly, to question the importance and treatment that the author carried out in favor of an understanding of the problems about the State and the Brazilian economic development.
\end{abstract}

Keywords: Development; sociopolitical thinking Brazil; Hélio Jaguaribe. 


\section{INTRODUÇÃO}

Os anos 20 do século XX é uma daquelas décadas que ficaram marcadas na história em função dos conjuntos de transformações sócio-políticas, econômicas e culturais ocorridas globalmente, principalmente quando pensamos o mundo ocidental e, consequentemente as influências e desdobramentos destes acontecimentos na América Latina e no Brasil em particular.

Neste contexto global e nacional, neste caleidoscópio que foi a década de 20 do século XX que nasceram três grandes pensadores brasileiros (Florestan Fernandes, Celso Furtado e Hélio Jaguaribe) que influenciaram a forma pela qual interpretamos o Brasil, principalmente a partir da segunda metade do século com os processos de industrialização crescentes no país.

Ainda que não vamos realizar um estudo comparado entre os autores, a confluência de temas e ideias entre os mesmos, de um lado e, o centenário de Fernandes e Furtado em 2020, são aspectos relevantes e merecem o registro neste artigo.

O sociólogo Florestan Fernandes que nasceu em 22 de julho de 1920 em São Paulo emorreu em 10 de agosto de 1995 em São Paulo aos 75 anos e que em 2020 marca o seu centenário. Sobre Florestan já há uma vasta produção bibliográfica, mas dois aspectos acreditamos ser relevantes para apontarmos, primeiro que Florestan é lido e reconhecido pela fortuna crítica como autor que produziu livros e obras clássicas em diferentes áreas das ciências sociais, citamos o livro "A função social da guerra na sociedade Tupinambá ", o livro "A integração do negro na sociedade de classes, vol.1 e 2"e o livro "A Revolução burguesa no Brasil: ensaio de interpretação sociológica”, este último tendo a publicação de sua 6a em 2020 (pela Editora Contracorrente) como parte das comemorações ao centenário do autor e livro inaugural da Coleção sobre Florestan Fernandes coordenada na editora por Bernardo Ricúpero. O livro ainda conta com prefácio de André Botelho e Antônio Brasil Jr. E posfácio de Gabriel Cohn. Em segundo, destacamos a ideia de sociologia e sociólogo engajado, onde o rigor científico e sociológico se articula com as consequências do fazer sociologia na sua reflexão e possibilidade de mudança social.

O economista e cientista social Celso Furtado que nasceu em 26 de julho de 1920 na Paraíba e morreu em 20 de novembro de 2004 no Rio de Janeiro aos 84 anos e 2020 também marca o seu centenário. Furtado, tal como Florestan, também possui uma obra relevante para as ciências sociais e para as interpretaçôes do Brasil, assim como também já há uma vasta produção bibliográfica sobre o autor e sua obra. Livros como "Formação Econômica do Brasil", "Desenvolvimento e subdesenvolvimento", "Subdesenvolvimento e estagnação na América Latina" e o "Mito do desenvolvimento econômico" 
entre outros, marcaram e influenciaram toda uma geração de intelectuais brasileiros e latino-americanos na segunda metade do século XX. Desde o início do século XXI, Rosa Freire d'Aguiar tem organizado a Coleção Celso Furtado com a nova edição de seus livros, assim como a publicação de material inédito, seja sobre a obra ou sobre elementos biográficos do autor.

E o cientista político Hélio Jaguaribe que nasceu em 23 de abril de 1923 no Rio de Janeiro e morreu em 9 de setembro de 2018 aos 95 anos. Embora Celso Furtado e Hélio Jaguaribe tenham feito formação em direito, fazem parte do rol de autores que nesta época, após cursar direito, enveredavam para outras áreas do saber no campo das chamadas ciências sociais em sentido mais geral. Daí o reconhecimento do Furtado na economia e do Jaguaribe na Ciência Política.

Neste artigo vamos dar ênfase a obra de Hélio Jaguaribe. O tratamento dado ao texto se insere numa aproximação de duas áreas do conhecimento na sociologia, a saber: a sociologia do desenvolvimento e o pensamento social. Neste sentido, a partir da obra de Hélio Jaguaribe nossa interpretação acaba por valorizar o texto e o contexto do autor, assim como suas intencionalidades e as derivaçóes interpretativas na maneira como o autor e sua obra foi e são mobilizadas na atualidade.

Para tal, o artigo será organizado com esta breve introdução, seguidas de três partes, asaber: uma breve caracterização biográfica do autor (nesta parte utilizamos além da bibliografia disponível, o acervo do Centro de Pesquisa e Documentação de História Contemporânea do Brasil - CPDOC); uma segunda, evidenciando a influência do autor para o pensamento sócio-político brasileiro por meio do como a obra do autor é mobilizada e, em terceiro, vamos problematizar, ainda que modestamente, a importância da chave política para a compreensão dos problemas acerca do Estado e do desenvolvimento econômico brasileiro.

\section{HÉLIO JAGUARIBE: FRAGMENTOS BIOGRÁFICOS E DE TRA- JETÓRIA}

Hélio Jaguaribe de Mattos, ou Hélio Jaguaribe como conhecido nos meios intelectuais e acadêmicos, foi um importante cientista social brasileiro, formado em Direito pela Pontifícia Universidade Católica do Rio de Janeiro em 1946. Todavia, sua obra apresentou contribuição relevante por meio da sua produção intelectual no campo da ciência política em debate com a sociologia, a economia e a história.

Em 1949, três anos após sua formatura, se torna responsável pelo suplemento cultural do Jornal do Comércio no Rio de Janeiro. Sua passagem pelo 
jornal vai ser fundamental para suas empreitadas futuras no que concerne a investigações e interpretações sobre e sociedade brasileira.

Funda em 1952, juntamente com um grupo de cientistas sociais de diferentes abordagens teórico-metodológicas o "Instituto Brasileiro de Economia, Sociologia e Política - IBESP”. O Instituto visava reformular e produzir uma nova interpretação sobre a sociedade brasileira nos seus múltiplos aspectos (sociais, políticos, econômicos e culturais). Durante este período, Hélio Jaguaribe foi secretário-geral e diretor da revista "Caderno de Nosso Tempo", periódico que apresentou forte relevância para o debate sobre o Brasil e a América Latina.

Em 1956, depois de uma curta, porém proveitosa e relevante experiência no IBESP, Hélio Jaguaribe contribui expressivamente para a criação do Instituto Superior de Estudos Brasileiros - ISEB, vinculado ao Ministério da Educação e Cultura à época. Vamos apresentar um pouco mais do debate envolvendo o Hélio Jaguaribe e o ISEB na terceira parte deste artigo.

Como muitos intelectuais brasileiros, Hélio Jaguaribe foi um crítico do golpe civil militar de 1964, o que o levou a sair do Brasil e ir para os Estados Unidos, regressando somente em 1969. No período em que esteve nos Estados Unidos, lecionou na Universidade de Harvard entre os anos de 1964 a 1966, na Universidade de Stanford entre os anos de 1966 a 1967 e, no Massachusetts Institute of Tecnology - MIT, entre os anos de 1968 a 1969.

No retorno ao Brasil em 1969, Hélio Jaguaribe passa a integrar o corpo docente e administrativo das Faculdades Integradas Cândido Mendes, sendo diretor de Assuntos Internacionais. A partir de 1979, com a criação do Instituto de Estudos Políticos e Sociais (Iepes) é designado decano e, permanecendo nesta função até 2003.

Em 1992, tem uma breve passagem pelo governo federal, assumindo entre abril e setembro a Secretaria de Governo de Ciência e Tecnologia, posteriormente alavancada ao status de Ministério.

Após esta passagem pelas instâncias governamentais, retorna a suas atividades exclusivamente acadêmicas, coordenando um projeto de pesquisa numa parceria interinstitucional entre o Iepes, a Universidade de São Paulo - USP e a Universidade de Buenos Aires - UBA. O projeto intitulado "A Critical study of history" visava revisitar e produzir novas análises acerca da história universal.

Foi honrado várias vezes pelo grau de Doutor Honoris Causa no Brasil e no exterior, destacamos os proferidos pela Universidade de Jahannes Gutenber, de Mainz, Alemanha em 1983, da Universidade Federal da Paraíba em 1992 e da Universidade de Buenos Aires em 2001. 
É eleito em 3 de março de 2005, a Cadeira n. 11 da Academia Brasileira de Letras, sucedendo Celso Furtado. Cadeira está que já foi ocupada por Darcy Ribeiro, Celso Furtado e atualmente é ocupada por Ignácio de Loyola Brandão. Um fato interessante é que a Cadeira n. 11 foi ocupada de outubro de 1992 a setembro de 2018 por autores oriundos das chamadas ciências sociais, mais especificamente, por um antropólogo, um economista e um cientista político conforme quadro 1 .

Quadro 1 - Cadeira N.11 da Academia Brasileira de Letras - Autores das Ciências Sociais

\begin{tabular}{|l|l|l|l|l|l|}
\hline Nome & $\begin{array}{l}\text { Data } \\
\text { Eleição }\end{array}$ & $\begin{array}{l}\text { Data } \\
\text { Posse }\end{array}$ & Quem Recebeu & Falecimento & $\begin{array}{l}\text { Área de } \\
\text { Conhecimento }\end{array}$ \\
\hline Darcy Ribeiro & $08 / 10 / 1992$ & $15 / 04 / 1993$ & $\begin{array}{l}\text { Candido } \\
\text { Mendes de Almeida }\end{array}$ & $17 / 02 / 1997$ & Antropologia \\
\hline Celso Furtado & $09 / 08 / 1997$ & $31 / 10 / 1997$ & Eduardo Portella & $20 / 11 / 2004$ & Economia \\
\hline Hélio Jaguaribe & $03 / 03 / 2005$ & $22 / 07 / 2005$ & $\begin{array}{l}\text { Candido } \\
\text { Mendes de Almeida }\end{array}$ & $09 / 09 / 2018$ & Ciência Política \\
\hline
\end{tabular}

Fonte: Academia Brasileira de Letras (ABL), (acesso em 10 de maio de 2020 - http://www.academia.org.br/academia/)

\section{HÉLIO JAGUARIBE: APONTAMENTOS BIBLIOMÉTRICOS}

Para apresentação quantitativa da produção acadêmica (Tese e Dissertaçôes) sobre o Hélio Jaguaribe ou sobre o ISEB (que envolve direta ou indiretamente o Hélio Jaguaribe) utilizamos o Portal de Teses da Capes (CatálogodeTeseseDissertações-http://catalogodeteses.capes.gov.br/catalogoteses/\#!/).

Existem no Brasil dois repositórios de Teses e Dissertaçóes, a saber: Portal de Teses da Capes (http://capesdw.capes.gov.br) que é o sistema online oficial e é vinculado ao Ministério da Educação (MEC) e o Banco de Teses do IBICT (http://bdtd.ibict.br/pt) que integra todas as bibliotecas digitais de teses e dissertações das universidades brasileiras que utilizam o sistema BDTD. Ainda que os dois repositórios propiciam a busca de Teses e Dissertaçóes feitas no Brasil, o Portal Capes é mais completo na catalogação das Teses e Dissertaçóes, sendo assim, optamos por fazer a busca no Portal da Capes.

Para as finalidades propostas neste artigo utilizamos, utilizamos dois conjuntos de palavras chaves para busca. Também fizemos uso de aspas nas palavras chaves a fim de afunilar as especificidades pretendidas. Numa primeira busca digitamos o nome do Autor, a saber: Hélio Jaguaribe e numa segunda rodada de buscas digitamos ISEB. Na primeira busca encontramos 13 (teses e dissertaçóes) e na segunda, encontramos 76 (teses e dissertaçóes). As apresentaçôes dos dados estão nos Quadros 2, 3, 4 e 5. 
Para evidenciarmos o como o autor é mobilizado na produção acadêmica, selecionamos duas variáveis, a primeira sendo a grande área do conhecimento (que organiza de forma mais geral os dados) e a segundo como área do conhecimento (que organiza de maneira mais específica os dados). Ambas as formas de categorização são previamente definidas pelo Portal de Teses da Capes.

Quadro 2 - Dissertação e Teses sobre Hélio Jaguaribe

\begin{tabular}{|l|c|c|c|}
\hline Grande Área de Conhecimento & Dissertações & Teses & Total \\
\hline Ciências Humanas & 09 & 03 & 12 \\
\hline Multidisciplinar & 01 & - & 01 \\
\hline Total & 10 & 03 & 13 \\
\hline
\end{tabular}

Fonte: Catálogo de Teses e Dissertações - CAPES (acesso em 07 de maio de 2020 - https://catalogodeteses.capes.gov. $\mathrm{br} /$ catalogo-teses/\#!/)

Quadro 3 - Dissertação e Teses sobre Hélio Jaguaribe - áreas de conhecimento

\begin{tabular}{|l|c|}
\hline Áreas do Conhecimento & Total \\
\hline Ciência Política & 07 \\
\hline Sociologia & 03 \\
\hline História & 01 \\
\hline Sociais e Humanidades & 01 \\
\hline Educação & 01 \\
\hline Total & 13 \\
\hline
\end{tabular}

Fonte: Catálogo de Teses e Dissertações - CAPES (acesso em 07 de maio de 2020 - https://

catalogodeteses.capes.gov.br/catalogo-teses/\#!/)

Evidencia-se que o autor é majoritariamente mobilizado na área de conhecimento das ciências humanas, onde as especialidades de Ciência Política e Sociologia correspondem por aproximadamente $80 \%$ das investigaçóes realizadas.

As Teses e dissertaçóes diretamente vinculadas a obra de Hélio Jaguaribe concentram-se majoritariamente nas investigações acerca da política e do desenvolvimento, esses dois temas em geral representam o maior interesse das autoras e autores que utilizam a obra de Jaguaribe para os problematizar acerca de algumas das questôes centrais presentes na sociedade brasileira.

Já as pesquisas sobre o ISEB em geral (Quadros 4 e 5), mostram que as especialidades da História e da Educação concentram individualmente as áreas com mais dissertaçóes e teses realizadas. Quando se soma as áreas de 
Sociologia e Ciência Política as da História e Educação, encontra-se aproximadamente $90 \%$ dos trabalhos produzidos sobre o ISEB nessas áreas de conhecimento.

É razoável afirmar que a obra de Jaguaribe em particular e as investigações a partir do ISEB em geral, representam uma importante mobilização do como o autor e o ISEB influenciaram a maneiro de como se pensa e problematiza os problemas vinculados de maneira geral a ideia de mudança social no capitalismo brasileiro. Mas também, evidencia que tal debate não ficou represado entre as décadas de 1950 a 1970, mas ainda servem de ponto de partida e reflexão sobre estratégias para o desenvolvimento, relação entre Estado e Mercado, formação educacional e reformas de base e institucionais no Brasil atual.

Quadro 4 - Dissertação e Teses sobre ISEB

\begin{tabular}{|l|c|c|c|}
\hline Grande Área de Conhecimento & Dissertações & Teses & Total \\
\hline Ciências Humanas & 46 & 23 & 74 \\
\hline Ciências Sociais Aplicadas & 02 & 01 & 03 \\
\hline Multidisciplinar & 02 & 01 & 03 \\
\hline Engenharia & 01 & - & 01 \\
\hline Total & $\mathbf{5 1}$ & $\mathbf{2 5}$ & $\mathbf{7 6}$ \\
\hline
\end{tabular}

Fonte: Catálogo de Teses e Dissertações - CAPES (acesso em 07 de maio de 2020 - https://catalogodeteses. capes.gov.br/catalogo-teses/\#!/)

Quadro 5- Dissertação e Teses sobre ISEB - áreas de conhecimento

\begin{tabular}{|l|c|}
\hline Áreas do Conhecimento & Total \\
\hline História & 23 \\
\hline Educação & 22 \\
\hline Sociologia & 13 \\
\hline Ciência Política & 11 \\
\hline Economia & 02 \\
\hline Sociais e Humanidades & 01 \\
\hline Administração & 01 \\
\hline Ciências Ambientais & 01 \\
\hline Engenharia de Produção & 01 \\
\hline Interdisciplinar & 01 \\
\hline Total & 76 \\
\hline
\end{tabular}

Fonte: Catálogo de Teses e Dissertações - CAPES (acesso em 07 de maio de 2020 - https:// catalogodeteses.capes.gov.br/catalogo-teses/\#!/) 
No site do Youtube (www.youtube.com.br) é possível encontrar algumas dezenas de vídeos envolvendo o Hélio Jaguaribe. Apenas para fins de ilustração, podemos dividir esses vídeos em 3 grandes subtemas. Primeiro, os vídeos de entrevistas e/ou fragmentos de entrevistas feitos com Hélio Jaguaribe ao longo de sua vida. Alguns dos temas mais explorados nesses vídeos são o do desenvolvimento e da política brasileira. Um segundo conjunto de vídeos se referem a seminários, congressos e comentários sobre a obra de Hélio Jaguaribe. Já num terceiro conjunto de vídeos citamos os de homenagem, principalmente após a sua morte. Ainda há o Documentário "Tudo é irrelevante: Hélio Jaguaribe", dirigido por Izabel Jaguaribe e Ernesto Baldan no ano de 2017, com 81 minutos de duração.

Há ainda duas outras formas de divulgação e mobilização do autor na produção acadêmica. A produção de artigos sobre o autor, cuja forma de acesso se daria pela busca de artigos nas bases de dados e periódicos nacionais e internacionais e sites especializados, tais como Scielo (https://scielo.org), Google Acadêmico (https://scholar.google.com.br/scholar?q=), a plataforma CAFe, vinculada ao Portal de periódicos Capes (http://www.periodicos. capes.gov.br/), entre outras.

O segundo, e de muita relevância para as investigaçóes acerca da obra de Hélio Jaguaribe é a Fundação Alexandre de Gusmão (FUNAG), instituída com base na Lei no 5.717 de 26 de outubro de 1971, é uma fundação pública vinculada ao Ministério das Relações Exteriores (http://funag.gov.br/index. $\mathrm{php} / \mathrm{pt}$-br/funag - acessado no dia 07 de maio de 2020). A FUNAG organizou a coleção sobre Hélio Jaguaribe apresentando sua obra em três conjuntos gerais de Temas, a saber: Estudos Filosóficos e Políticos; Introdução ao Desenvolvimento Social e O Nacionalismo na Atualidade Brasileira. Os três eixos temáticos de textos do autor não contemplam toda sua publicação, mas envolve grande parte dela, não somente as produzidas em artigos e capítulos de livros, mas também as conferências, aulas magnas, entre outras atividades do autor. Os textos visam dar um panorama que percorre escritos do autor entre os anos 1950 até aproximadamente 2013, ano de publicação da Coleção da FUNAG.

A FUNAG ainda publicou uma organização de artigos sobre o Hélio Jaguaribe intitulada "Visóes da obra de Hélio Jaguaribe" que foi organizada por Sérgio Eduardo Moreira Lima em 2015 e contou com homenagem a Hélio Jaguaribe de Fernando Henrique Cardoso e Luiz Inácio Lula da Silva, além de artigos de Celso Lafer, Candido Mendes, Aldo Ferrer, Samuel Pinheiros Guimarães e João Paulo de Almeida e de transcrição de agradecimentos do próprio Hélio Jaguaribe. 
Como evidenciado, além da própria obra de Hélio Jaguaribe que contempla mais de 40 publicações editadas em português, inglês e espanhol (FUNTAG, 2015). Ainda há vasto material bibliográfico e audiovisual disponível para análise e investigação sobre as proposições, visões, ensaios e reflexões do autor sobre o Brasil, a política e o desenvolvimento como chaves interpretativas.

Por fim, a revista eletrônica Insight Inteligência, edição 75 de outubro a dezembro de 2016 publicou um caderno especial sobre Hélio Jaguaribe intitulado: "Especial: o Brasil superior de Hélio Jaguaribe" e contou com os seguintes artigos: "Jaguaribe em construção: uma leitura da política brasileira em dois tempos" de Angélica Lovatto, "Cadernos para todos os tempos: a encruzilhada entre o atraso e o progresso" de Cristina Buarque de Holanda e um texto do próprio Hélio Jaguaribe intitulado "Usina de altos estudos: liçôes sem prazo de validade".

\section{CONTEXTOS E IMPLICAÇÕES: REFLEXÕES ACERCA DO DESEN- VOLVIMENTO ENTRE AS DÉCADAS 1930 A 1970}

O período histórico entre as décadas de 1930 a 1970 marcaram um conjunto de transformações econômicas, políticas, sociais e culturais em esfera mundial $^{2}$. Alguns acontecimentos, tais como o fim da Segunda Guerra Mundial, os acordos de Bretton Woods, o Plano Marshall e posteriormente, na década de 1960 a Aliança para o Progresso expressam bem o quanto este período caracteriza um conjunto de mudanças em torno da temática do desenvolvimento. Seja com políticas e acordos internacionais para criação de regras e padróes para a dinâmica econômica internacional (envolvendo o Estado-nação e o comercio internacional), seja para a reconstrução europeia do pós-guerra ou pela disponibilidade de crédito via cooperação para intensificação do crescimento econômico (industrialização e desenvolvimento) dos países latino-americanos.

No plano das políticas e orientaçôes econômicas oriundas das recém-criadas agências multilaterais (ONU, BIRD, FMI), como das condutas e práticas dos Estados nacionais, a questão do desenvolvimento econômico se torna central. Nos países desenvolvidos como forma de reconstrução econômica de alguns países impactados drasticamente pela segunda guerra mundial e, para outros, como forma de avançar no desenvolvimento e crescimento econômico sem correr os riscos de replicar as crises capitalistas das décadas de 1920/30 (Grande Depressão iniciada em 1929 e arrastada pela década de 1930). Por outro lado, os países latino-americanos adentram na agenda para 
impulsioná-los em rumo do propalado desenvolvimento e crescimento econômico via estratégia industrial.

Muitos foram os esforços realizados entre as décadas de 1930 e 1970 em compreender e explicar o capitalismo e as transformações econômicas, políticas, sociais e culturais pelas quais os diferentes países do mundo (ocidental e oriental, os do Norte e do Sul, os desenvolvidos e os subdesenvolvidos ${ }^{3}$ ) estavam passando. A questão do capitalismo neste sentido estaria vinculada a um determinado padrão de industrialização, a um tipo particular de organização burocrática do Estado e um conjunto de transformações sócio-políticas, culturais e econômicas vinculadas à ideia da mudança social, principalmente no que se refere às mudanças, ou em andamento ou em perspectiva, nos países subdesenvolvidos neste período (industrialização, modernização do rural, integração de indivíduos e classes sociais ao consumo, reforma agrária e mobilidade social, por exemplo).

Autores da história econômica, da sociologia, da ciência política e áreas correlatas das humanidades elaboraram grandes esforços analíticos e históricos no interesse explicativo einterpretativo acerca do desenvolvimento, do crescimento econômico, da industrialização e das formas de superação do atraso econômico pelos países que se encontravam em condições de baixo crescimento econômico. Cada vez ficava mais difícil justificar o desenvolvimento pela divisão internacional do trabalho, ou seja, que no comércio internacional a lógica das vantagens comparativas naturalmente levaria a todas as nações se beneficiarem das transformações tecnológicas e circulação de mercadorias em esfera global.

Com o intuito de problematizar esta questão, Agarwala e Singh organizaram uma coletânea em $1958^{4}$ (A economia do subdesenvolvimento) contendo inúmeros autores de diferentes matrizes teóricas e metodológicas que durante a década 1950 (exceção ao texto de Rosenstein-Rodan de 1943) acabaram por redefinir o campo de investigação da economia do desenvolvimento. O Livro foi organizado em seis partes e visava contemplar os principais fatores que permeavam o debate nos anos 1950.

Já o historiador econômico russo Alexander Gerschenkron, organizou um conjunto de reflexóes, principalmente a partir das discussóes do seu principal texto ( $\mathrm{O}$ atraso econômico em perspectiva histórica) acerca do desenvolvimento das economias e suas respectivas diferenças e desigualdades, principalmente por aferir que o desenvolvimento dos países retardatários seguiria características próprias e específicas nos seus processos de industrialização. A inovação analítica e metodológica do autor resultaria na superação de dois dos principais arcabouços teórico-metodológicos na história econômica durante a década de 1950 . O autor propóe a superação, ainda que a partir do 
diálogo crítico com a teoria marxista e a rostowiana, ou seja, refuta a centralidade explicativa da luta de classes na dinâmica da história no marxismo e, ao mesmo tempo, não aceita o etapismo universal e com passos comuns da abordagem de Rostow. $\mathrm{O}$ atraso econômico neste sentido seria tratado de forma comparativa e portador de uma dialética onde o atraso relativo referenciava simultaneamente problemas e oportunidades. Por outro lado, a industrialização retardatária seria um processo descontínuo e com forte necessidade de participação do Estado-Nação neste processo. O livro recém-publicado no Brasil "O atraso econômico em perspectiva histórica e outros ensaios" evidencia o conjunto de suas discussóes em 12 artigos que compóem o livro

Simultaneamente ao debate na Europa e nos Estados Unidos dos pós anos 1940, há um conjunto de reflexões produzidas no Sul, entre elas, as reflexões Latino-Americanas, do leste asiático e da África. Dado este protagonismo de autores vinculados às naçôes periféricas, por um lado e o contesto histórico-econômico, político, social e cultural vivenciado em esfera global no pós guerra, pode-se afirmar que a temática do desenvolvimento e do subdesenvolvimento assume papel de destaque tanto nas produções intelectuais de diferentes matrizes teórico-metodológicas, como também no planejamento e programas de políticas públicas e investimentos infra estruturais em prol do chamado desenvolvimento dos países em condição (e/ou situaçôes concretas) de subdesenvolvimento. 
Neste sentido, muitos autores passaram a elaborar uma explicação e/ou interpretação das respectivas condições materiais de desenvolvimento das economias capitalistas nos diferentes e desiguais Estados Nacionais (epistemologicamente vamos classificar para fins de análise a partir da nomenclatura Norte e Sul, no intuito de indicar que a posição geográfica e territorial também expressa condiçốes materiais distintas e hierarquizadas, marcando não somente uma dominação econômica, como também uma ideologia de dominação social, política e cultural). Furtado (1978) no livro "Criatividade e dependência na civilização industrial” dedica um capítulo a esta reflexão afirmando que no campo das ideias, mas também da política e práticas sociais (econômicas e culturais) a história do capitalismo a partir da revolução industrial marcaria um crescente processo de mudanças de ideologias, porém, não dos seus abandonos. Ao passo que o final do século XIX e começo do século $\mathrm{XX}$ a ideologia dominante seria a do progresso (realização do individuo iluminista e generalização das riquezas entre as naçóes), a partir da segunda metade do século XX, a ideologia que assume forma hegemônica seria a do desenvolvimento.

Sunkel e Paz (1970) ao analisarem sobre os conceitos de desenvolvimento e subdesenvolvimento, principalmente sobre as influências externas na América Latina e como o pensamento latino americano significou e explicou a sua própria condição na divisão internacional do trabalho acabou por valorizarem na reflexão três conceitos (também presentes nos constructos cepalinos), a saber: sistema, estrutura e processo. Somente a partir de uma análise que valorizasse os três conceitos que se alcançaria uma interpretação condizente com as díspares realidades com que os países desenvolvidos e os subdesenvolvidos (entre eles, os latino americanos) possuíam. Peña (1971) similarmente ao problematizar a condição mexicano no período, acaba por vincular que a relação de dependência externa na correlação de produção e reprodução simultânea do desenvolvimento e do subdesenvolvimento em esfera global acaba por aprofundar os fatores estruturais do subdesenvolvimento, ou seja, as ideias de sistema, estrutura e processo também se encontram na análise, ainda que não cunhadas textualmente na obra do autor.

Porém, não é exclusividade do campo das ciências econômicas o tratamento e análise acerca da temática do desenvolvimento, as ciências sociais e humanidades em geral e, a sociologia, ciência política e história em particular, vão apresentar uma esforço analítico fundamental para a explicação, compreensão e interpretação sobre o desenvolvimento e subdesenvolvimento, sobre a dinâmica particular do chamado por alguns de "Terceiro Mundo", sobre a questão da mudança social e da modernização, entre outras formas de tratamento reflexivo e crítico sobre a temática em voga. 
Alguns autores ao distinguirem crescimento e desenvolvimento, acabaram por criticar a ideia de que exista um processo universal e geral, ou seja, as dinâmicas endógenas são fundamentais para entender as trajetórias percorridas por cada país. Neste sentido, como salienta Perroux (1961), são as mudanças das estruturas mentais e dos hábitos (costumes etradiçôes) sociais, vinculados as transformaçóes institucionais (política) é que garante a longo prazo a sustentação do desenvolvimento e, consequentemente, o avanço e crescimento do produto global, ou seja, as práticas dentro do escopo acima propiciam os avanços em escala global e esses por sua vez, enquanto totalidades sociais garantem os avanços particulares.

Já outros autores, tais como: Hagen (1969), Costa Pinto (1963), Lewis (1960), vão focar a análise na ideia de mudança social, seja pela passagem de sociedades tradicionais para sociedade industriais, marcadas por uma mudança tecnológica expressiva ou pela necessidade de mudança no interior de sociedades e Estados altamente desiguais, rurais e com baixo crescimento econômico e alta dependência externa. Por sua vez, Touraine (1989 e 2005), ao valorizar os atores e as instituiçóes na análise do desenvolvimento, evidencia a relevância do problema do processo social (de forte articulação endógena também). Blumer (1939), Merton (1958) e Casanova (1967) são outros autores, que com diferentes análises, enfocam a importância da dinâmica dos movimentos sociais e/ou grupos de referencias como fatores fundamentais para a mudança.

Por outro lado, as discussóes sobre o desenvolvimento no século $\mathrm{XX}$ adquiriram duas perspectivas não excludentes entre si em termos gerais, poderíamos até chamar de construção de novos paradigmas ou mesmo de produção de duas epistemologias, a saber: uma primeira voltada para o entendimento e explicação do capitalismo, neste sentido, não haveria desenvolvimento, subdesenvolvimento, dependência, industrialização, modernização e mudança social senão características de produção e reprodução do capitalismo (enquanto totalidade e como particularidade concreta). A outra, vinculada as diferentes abordagens teórico-metodológicas que surgem como portadoras da interpretaçốes e explicaçốes do mundo, e do capitalismo e suas diferentes condições de desenvolvimento esubdesenvolvimento em particular, aqui apontamos a marxista, a economia clássica e neoclássica, a weberiana, a funcionalista, a estrutural-funcional, assim como a cepalina, as dualistas, as da dependência (weberiana e marxiana), entre outras.

Muitos outros autores, de diferentes matrizes teóricas vão voltar seus esforços para o entendimento do capitalismo e nele a questão do desenvolvimento no processo histórico é variável central. Aqui citamos Nurkse (1957); Myrdal (1957) Lewis (1956); Boyer (2004), mas também, Furtado 
(1978, 2008 e 2009); Bielschowsky (2000); Rodríguez (2009) entre outros. No âmbito latino-americano em particular, citamos Pereira (1977), Jaguaribe (1969), assim como os livros organizados e compilados sobre a temática, tais como "La dominación de América Latina" compilado por José Matos Mar em 1968 e contou com capítulos de Jaguaribe, Furtado, Faletto, Di Tella, Espartaco, Sunkel e Cardoso. O livro “O Estado na América Latina”organizado por Paulo Sérgio Pinheiro e com capítulos de O’Donnel, Rivas e Cardoso, o Livro "Sociologia do Desenvolvimento II, organizado por José Carlos Garcia Durand e Lia Pinheiro Machado e com capítulos de Blumer, Casanova, Lerner, Frank, Machado e Soares, entre outros livros e compilações que articulavam os principais intelectuais que produziram reflexões sobre o tema do desenvolvimento, subdesenvolvimento e da dependência na América Latina e, no Brasil, em particular.

Ao passo que essas reflexões e análises marcaram uma inflexão importante entre os anos 1930 a 1970, há um retorno do debate, ainda que com contextos e processos globais distintos (globalização e revolução tecnológica, por exemplo) no final do século XX e início do século XXI. Tal retorno não é apenas metodológico ou teórico, é também material, uma vez que parte dos problemas econômicos e sociais (pobreza e desigualdades, por exemplo) ainda permanecem como obstáculos a serem superados por parte expressiva de países no mundo, entre eles os Latino Americanos (mesmo os que passaram por um alto processo de industrialização).

Este movimento de reordenamento material, econômico, político, social e cultural também contou com um conjunto de reflexôes intelectuais e técnicas em torno das escolhas e estratégias necessárias à realização bem-sucedida de colocar os países subdesenvolvidos (ou atrasados) do capitalismo pós Segunda Guerra Mundial em rumo da prosperidade, do desenvolvimento econômico e social. O crescimento econômico, o aumento do bem-estar social e desenvolvimento humano, a modernização e a eliminação da dependência são algumas das concepções e dimensões contidas nos debates entre os anos 1930 e 1970 em esfera global, com um crescente protagonismo destas discussões na América Latina, seja em órgãos ou instituiçóes multilaterais, em institutos e centros de investigação criados ou nas universidades.

Neste sentido, o debate que esteve presente entre os anos de 1930 a 1970 marcaram significativamente os problemas que a sociedade brasileira e o capitalismo no Brasil estavam experimentando. Quando mobilizamos a obra de Jaguaribe fica evidente que o aporte do autor visa compreender os entraves e as potencialidades, assim como quais estratégias poderiam ser adotadas para a superação dos constrangimentos econômicos, sociais e políticos no Brasil. 
É neste contexto complexo e de circulação de intelectuais latino-americanos e brasilianistas que Hélio Jaguaribe se encontra, interage e se integra por continuidades e descontinuidades presentes em suas reflexões, em sua obra.

\section{HÉLIO JAGUARIBE E O ISEB: BREVES APONTAMENTOS}

Hélio Jaguaribe a partir do diálogo com a ciência política e sociologia alemã, principalmente a de influência weberiana, vai analisar o problema do desenvolvimento como uma questão eminentemente política, logo, localizada preferencialmente no âmbito do Estado-nação, onde a condução racional de estratégias para o desenvolvimento via planejamento estatal era central em sua análise. Fica evidenciado na obra do autor que sua interpretação valoriza as estratégias vinculadas aos tipos de açôes sociais realizadas, mas também reforça a importância das instituiçóes neste processo.

Durante a década de 1950, Jaguaribe foi fundamental para a criação do Instituto Superior de Estudos Brasileiros - ISEB. A partir de 1949, Jaguaribe a frente do Jornal doCommercio/Rio de Janeiro onde apresentava algumas ideias e reflexóes sobre o Brasil, seus problemas e crises a serem superadas, sejam nos aspectos econômicos, políticos ou sociais.

No ano de 1952 vários intelectuais das ciências sociais brasileira presentes no eixo Rio de Janeiro e São Paulo começam a se reunir de forma sistemática no Parque Nacional de Itatiaia para discutir os problemas do Brasil. O primeiro nome do grupo acaba sendo Grupo Itatiaia. O local do encontro, das reunióes do grupo foi escolhido estrategicamente por estar no meio entre as cidades do Rio de Janeiro e de São Paulo, cidades que contemplavam os intelectuais vinculados ao grupo.

Os intelectuais do Rio de Janeiro eram: Hélio Jaguaribe, Candido Mendes de Almeida, Alberto Guerreiro Ramos, Oscar Lourenço Fernandes, Ignácio Rangel, José Ribeiro de Lira, Israel Klabin, Cid Carvalho, Fábio Breves, Ottolmy da Costa Strauch, Heitor Lima Rocha e Rômulo Almeida, entre outros.

Os intelectuais de São Paulo eram: Vicente Ferreira da Silva, Ângelo Simões de Arruda, Almeida Salles, Paulo Edmur de Souza Queiroz, José Luiz de Almeida Nogueira Porto, Miguel Reale e Luigi Bagolin, entre outros.

A composição do Grupo Itatiaia caracterizava-se por diferentes orientaçôes Ideológicas e Políticas, ou seja, seus membros não tinham unidade teórica, pelo contrário, compunham-se de intelectuais das mais diversas filiaçóes teóricas, weberiano, marxistas, culturalistas, entre outras. Todavia, atuavam em conjunto em função do problema da necessidade de aceleração do processo de Desenvolvimento Econômico Brasileiro, ou seja, o tema, ou 
questão do Desenvolvimento acabava por unificar o grupo (ao menos por um período). Era pretensão do Grupo Itatiaia o assessoramento governamental via elaboração de projetos e propostas que visassem a superação do atraso econômico brasileiro.

Para estruturar as atividades do Grupo Itatiaia, criou-se um Instituto Brasileiro de Economia, Sociologia e Política - IBESP, financiado com recursos provenientes de Hélio Jaguaribe em 1952. O IBESP passa a publicar a Revista Cadernos do Nosso Tempo para veicular as ideias do grupo. Em 1955 o IBESP se transforma em ISEB, vinculado ao Ministério da Educação e da Cultura, embora com dotação orçamentária muito baixa. O marco fundador foi às conferências reunidas sob o título de "Introdução aos problemas brasileiros"

O ISEB era organizado em cinco departamentos:

a) Ciência Política: Hélio Jaguaribe

b) Economia: Ewaldo Correia Lima

c) Filosofia: Álvaro Vieira Pinto

d) História: Candido Mendes

e) Sociologia: Guerreiro Ramos

No ano de 1956 o ISEB começa a ofertar cursos regulares no MEC. Porém, o ISEB vai passar por uma crise no ano de 1958, decorrente do livro "O nacionalismo na atualidade brasileira" de Hélio Jaguaribe. O principal fator da discordância foi o debate entre Jaguaribe a Guerreiro Ramos acerca da importância do capital estrangeiro e da privatização do setor petroquímico para o desenvolvimento brasileiro - embate entre um capitalismo nacional ou capitalismo a partir do capital estrangeiro. Deste processo resultou à saída de ambos do ISEB. Pode-se resumidamente descrever o funcionamento do ISEB por períodos curtos vinculados a uma determinada forma de atuação. O período de 1959-1960 o ISEB centra-se nos cursos extraordinários e com forte influência dos setores organizados da sociedade civil - sindicalistas, estudantes e setores militares, por exemplo. No período de 1961-1964 pode ser caracterizado por maior engajamento ${ }^{5}$ social e político e também pela sua extinção. O envolvimento do ISEB na campanha pelas Reformas de Base proposta por João Goulart - 1961-1964 é aspecto central para a extinção do ISEB, que desde a formação, enfrenta dificuldades financeiras, ou seja, sempre teve um aporte financeiro muito restrito (TOLEDO, 2005).

Apesar de fases distintas, o ISEB centra-se no problema do capitalismo brasileiro, ou no desenvolvimento brasileiro via planejamento e investimento estatal, o papel do Estado na promoção capitalista/industrial brasi- 
leira é central. Também visa a reflexão intelectual com a prática das políticas governamentais.

Todavia, os debates e reflexóes sobre o ISEB no Brasil ocupou um espaço relevante da intelectualidade do país. Tal como o ISEB que era composto por intelectuais, em sua maioria não acadêmicos e de diferentes orientações teóricas, assim como também por várias correntes ideológicas. A crítica e reflexão sobre o ISEB também contou com uma diversidade muito grande de orientações teóricas, com isto as leituras do que foi o ISEB, sua importância ou mesmo suas Ideologias foram problematizadas por autores de abordagens teóricas muito distintas. Teve importância neste debate crítico Toledo, 1977, Abreu, 2005, Pereira, 2005 Bresser-Pereira, 2004, entre outros. As publicaçôes sobre o ISEB ou sobre os autores isebilianos facilmente passam de uma centena no Brasil.

Não visava-se aqui, esgotar o debate acerca da relação do ISEB com Hélio Jaguaribe, mas apenas contextualizar a trajetória do autor, no qual a criação, debate, crise e extinção do ISEB são aspectos fundamentais.

Por um lado, Hélio Jaguaribe (e sua atuação no ISEB em particular) vai centrar seus esforços analíticos e intelectuais sobre os problemas brasileiros da década de 1950, onde a questão do desenvolvimento econômico e políticos são peças chaves. Neste percurso o autor vai se apoiar muito mais na influência germânica do que francesa (dos intelectuais do passado) para suas reflexões.

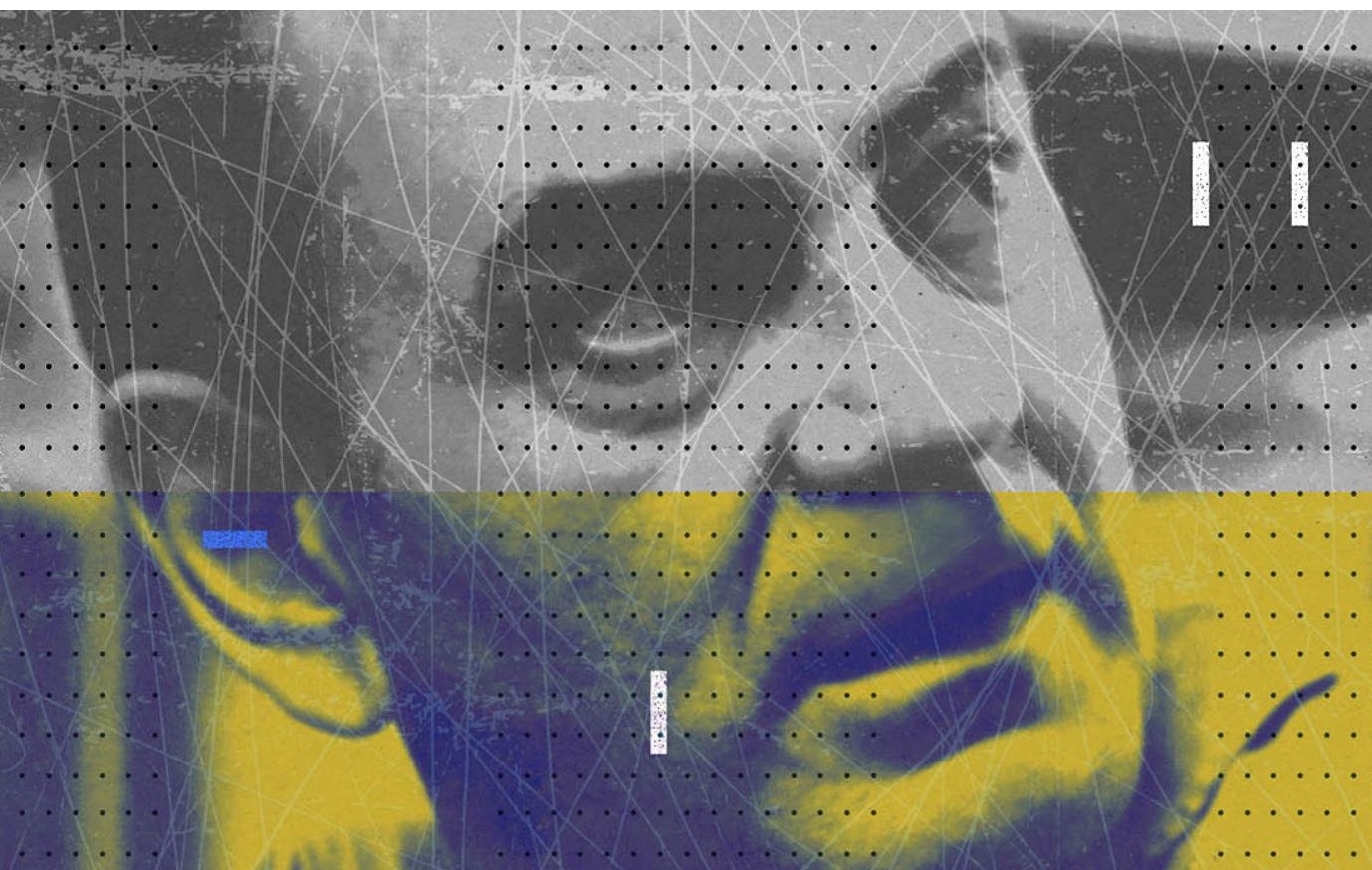




\section{HELIO JAGUARIBE E A QUESTÃO DO DESENVOLVIMENTO}

Helio Jaguaribe (1953; 1956a; 1956b; 1968) identificava uma crise das ideias no século XX a partir da observação da Europa, todavia, sua atenção maior voltou-se para o Brasil, entendido como partícipe da crise ocidental. Neste sentido, as análises do autor concernente a mudança social, principalmente as vinculadas ao crescimento das cidades e a expansão da indústria era resultado da desagregação da economia rural baseada no latifúndio. Segundo Weffort (2006), esse descompasso entre o rural e o urbano-industrial no que concernem às necessidades sociais e culturais na perspectiva de Jaguaribe reforça a importância da cultura na análise sobre os problemas do Brasil.

Jaguaribe (1954; 1956b; 1958a; 1958b;), ao apoiar sua ciência política e sociologia com a perspectiva econômica embasada em Celso Furtado, identificou que alguns fatores históricos funcionaram como condicionantes para as mudanças que começaram a ocorrer de maneira mais intensa a partir da década de 1930. Fatores como a lei de repressão ao tráfico de escravos (1850) e a lei da abolição da escravatura (1888), além das reorientações econômicas decorrentes da crise de 1929, levariam o Brasil a perseguir uma trajetória cada vez mais centrada no mercado interno, ou seja, estariam dadas as condiçóes para transferir para dentro do país a dinâmica da economia (WEFFORT, 2006).

Outros fatores também contribuiriam para o autor, ao dificultarem a importação dos produtos/mercadorias necessárias ao consumo interno no Brasil, seriam as guerras mundiais (primeira e segunda) e as crises cambiais. Neste processo de crise, a indústria passava gradativamente a substituir as importaçôes de bens de consumo e, em posteriormente, dos bens de produção.

Hélio Jaguaribe (1956b; 1968) divide a história do Brasil em 3 níveis de desenvolvimento, o primeiro e mais longo (cerca de três séculos e meio) foi a condição de colônia. O segundo, a partir de aproximadamente 1850 até meados da década de 1930 seria caracterizado pela fase semicolonial. Da década de 1930 para frente o país entraria na fase do desenvolvimento nacional, marcado pela intensificação do urbano e do industrial.

Porém, esta terceira fase de desenvolvimento nacional no Brasil também seria portadora de contradiçóes ou de incertezas, se por um lado, o passado, a história e as transformações pelas quais o país passou desde colônia foram fundamentais para o surgimento do desenvolvimento nacional, também trouxeram pontos de estrangulamentos (econômicos e sociais) capazes de bloqueá-lo ou mesmo abortá-lo. No plano político, das instituições também havia pontos de estrangulamentos, principalmente na lentidão do Estado dar respostas, ou pela permanência da chamada política de clientela, uma 
persistência do patrimonialismo num Estado que adquire padrões de racionalidade burocrática.

Para Jaguaribe haveria no Brasil um descompasso e estrangulamento entre a formação da poupança e a aplicação de investimentos com as chamadas necessidades econômicas e sociais da população em geral. No aspecto social em particular, o desenvolvimento brasileiro sofreria estrangulamentos pela permanência de privilégios de classe, sendo que esses privilégios alcançavam permeabilidade e forma na política de clientela no âmbito do Estado.

A questão do desenvolvimento brasileiro assume no autor dois níveis distintos, mas complementares, um teórico global centrado na racionalização dos processos econômicos, políticos, sociais e culturais e, outro empírico de análise dos progressos e obstáculos presentes no Brasil. Haveria uma relação quantitativa e qualitativa no desenvolvimento, onde as expressóes econômicas estariam em interdependência com as expressóes políticas, culturais e sociais em sentido mais amplo.

O fator prático ou empírico extraído daí se vincula à necessidade de pensar e implantar o planejamento estatal, associado à reforma no âmbito político (no Estado) como o principal gerador de transformaçóes sociais no país, no caso em particular, promover o tão propalado desenvolvimento brasileiro (econômico, político, social e cultural).

Ainda que o desenvolvimento possa ser entendido num sentido global para Jaguaribe, a forma interna deste processo no Brasil estaria vinculada à atuação, em situação de interdependência, das diferentes classes sociais ou fraçóes da sociedade que conseguiam imprimir suas demandas e interesses no âmbito do Estado. Mesmo considerando a necessária participação de todas as classes no processo, fica evidente que caberia papel central a burguesia industrial para a transição de uma situação de semicolonialismo para a de desenvolvimento nacional.

Partindo de um aporte weberiano, de um lado, e de uma lógica dualista estrutural (arcaico e moderno), de outro, o autor evidencia que as transformaçôes em prol do desenvolvimento decorreriam da atuação de todos os setores e classes da sociedade brasileira interligada por suas respectivas situações de classe nas diferentes dimensóes (econômica, política, social e cultural). Neste sentido o debate e/ou luta deveria se dar menos entre classes e mais no interior das classes.

As questóes acerca do desenvolvimento e do nacionalismo via planejamento estatal, ou seja, a reforma na esfera da política (Estado) como fundamental para este processo caracterizou o fundamento pelo qual Jaguaribe discordava dos nacionalistas mais radicais ao afirmar que a utilização do capital estrangeiro é central para a promoção do desenvolvimento nacional. 
O capital estrangeiro não seria uma força oposta ao nacional, mas sim apenas uma força externa. Mais uma vez este argumento reforça a dimensão global que o autor quer dar ao desenvolvimento, mesmo quando analisado na particularidade, como no caso do desenvolvimento brasileiro.

A forma e conteúdo da reforma política necessária a este processo se daria pela transição do Estado Cartorial, centrado no clientelismo e com isto, reiterador do atraso brasileiro. Já o Estado Funcional marcaria uma política ideológica voltada para o nacional, ainda que não visto em oposição ao investimento estrangeiro. A ideologia nacional tem uma força de eficácia e objetividade assumidas nas formas institucionais fundamentais ao desenvolvimento do país.

Por fim, mas não esgotando o debate sobre o autor, há íntima relação entre desenvolvimento econômico e desenvolvimento político, que assumem uma dupla condição, uma geral, enquanto desenvolvimento global e, outra particular, ou seja, como movimento inerente à realidade cultural de um determinado país. Nesta segunda parte do movimento, poderia se dizer que ao ocorrer como particularidade, ocorreria simultaneamente como realização também do global, porém com as possibilidades de progressos e estrangulamentos dados no plano interno.

Daí que no livro "Desenvolvimento Econômico e Desenvolvimento Político" há a defesa da escolha do modelo de nacional capitalismo como a trajetória a ser percorrida pelo Brasil. Do ponto de vista típico ideal, haveria duas formas de engendrar o capitalismo, uma espontânea vinculando ao desenvolvimento ao livre movimento do mercado. Outra que o autor chama de Bismarchiana ${ }^{6}$, onde a atuação do planejamento estatal é fundamental, ou seja, o desenvolvimento, inclusive o econômico, estaria em relação de interdependência com o da política. Porém, para a existência do nacional capitalismo é preciso que já se tenha em curso no país um desenvolvimento econômico com a liderança do empresariado burguês e de um Estado fortemente atuante no planejamento. Ambos os tipos expressariam tipos globais de racionalização.

Evidencia-se na obra de Jaguaribe, assim como em muitas das entrevistas que o autor deu durante a sua vida, que o debate do desenvolvimento brasileiro durante o período de existência do ISEB e as décadas seguintes (1970 e 1980) marcaram um processo onde se pensava o desenvolvimento vinculado à ideia de transformação do capitalismo no país. Esta chave, denominada em termos gerais de nacional desenvolvimentismo para o autor, marcaria a necessidade e o entendimento de que qualquer mudança da sociedade brasileira viria somente com o desenvolvimento do capitalismo no Brasil. Por sua vez, tal raciocínio contém múltiplas ideias e questôes que perpassaram como 
aspectos centrais a aliança entre o Estado e o mercado, expresso no capital (nacional e internacional). Do Estado viria o planejamento e do mercado a dinâmica econômica e como aspectos secundários estaria a necessidade de pactos de classes e de estratégias em prol do desenvolvimento articulando os múltiplos atores sociais, econômicos e políticos da sociedade brasileira.

Neste sentido, parece ter um sintonia fina, ainda que muitas vezes não declarada, entre os autores que estão produzindo entre os anos 1950 a 1970 sobre a temática do desenvolvimento brasileiro, tais como Celso Furtado, Florestan Fernandes, Fernando Henrique Cardoso, Otávio Ianni, Francisco Weffort, Guerreiro Ramos, entre outros, ainda que com diferenças entre si, viam na consolidação do capitalismo brasileiro o melhor caminho para as transformaçôes sociais que o país precisava, ou seja, na dinâmica da história em que os referidos autores pensavam, o Brasil precisaria ter atores (e/ou sujeitos) dinâmicos e fortes para poderem disputar projetos de país de maneira a ser integrativo, mesmo nos limites históricos imposto pelo capitalismo. A superação do subdesenvolvimento, a modernização do país, as mudanças estruturais, a industrialização, entre outros aspectos, estaria intimamente ligada à densidade e dinâmica que o capitalismo assumiria na sociedade brasileira em relação e correspondência com o Estado via planejamento. E desta relação de cumplicidade, porém não sem tensôes, seria gerado o tão propalado desenvolvimento do país com algum grau de correção das assimetrias sociais e econômicas entre as classes sociais e regióes brasileiras.

Por outro lado, Jaguaribe entende que a dinâmica do capitalismo brasileiro se estruturaria numa dupla dimensão, a saber: a nacional com todos os atores e implicaçôes envolvidas e a global em termos de fluxos de produção e reprodução capitalista, ambas como marcadores de racionalidade. Mais uma vez o autor e muitos dos seus contemporâneos aqui citados, dialogam em suas abordagens com o universal/global e o nacional/regional, ou seja, articulam simultaneamente ideias de totalidades e particularidades históricas para se pensar e interpretar o capitalismo brasileiro.

\section{CONSIDERAÇÕES FINAIS}

Reforçamos aqui nas consideraçôes finais a importância de Helio Jaguaribe para opensamento social e político brasileiro, a trajetória do autor e os temas de investigação escolhidos pelo mesmo o colocam em sintonia com o debate do seu tempo sobre os principais desafios da sociedade brasileira, assim como também, os possíveis caminhos a serem trilhados. Neste sentido, Jaguaribe não se contentou em ser um interprete, mas também visou construir ou indicar caminhos para a mudança, seja na sua vida intelectual ou nos seus 
múltiplos envolvimentos com instituições e agentes do Estado, tais como sua participação no ISEB e a importância deste para a implantação de um tipo particular de nacional desenvolvimentismo que acabou por influenciar o governo de Juscelino Kubitschek (1956-1960), a elaboração do projeto "Brasil 2000" para o governo de José Sarney, ou ainda, sua participação na secretaria de Ciência e Tecnologia do governo Fernando Collor de Melo.

Jaguaribe apresentou uma abordagem sociológica e política que visava interpretar o desenvolvimento, ou necessidade de desenvolvimento brasileiro (e latino-americano), ainda que por meio de influência de análises e teorias europeias, a partir da particularidade regional em que se inseria a análise, ou seja, interpretar a partir da América Latina os processos pelos quais a própria região vinha passando trouxe especificidades na obra do autor.

Jaguaribe ainda estabeleceu seu modelo interpretativo a partir da América Latina, ainda que sobre grande influência das abordagens teóricas germânicas e relaciona o problema do econômico ao problema da política, todavia, a partir do movimento da burguesia nacional e do papel planejador do Estado. No entanto, seu nacionalismo não é excludente com o capital estrangeiro, sendo este último apenas visto como de fora, porém, necessário ao desenvolvimento nacional.

Por fim, Jaguaribe se encontra ao lado dos autores que produziram interpretaçóes sobre o Brasil e que exerceram grande influência na formação de toda uma geração de cientistas sociais, principalmente quando se trata do tema do desenvolvimento e capitalismo brasileiro, mantendo até os dias atuais elementos e chaves analíticas interessantes para problematizar as condições sociais, econômicas e políticas do Brasil em particular e da América Latina em geral. Embora, a partir de 2013 as orientações de política econômica no Brasil começam a gradativamente incorporar um viés mais liberal no sentido pró mercado que se intensificaram no impeachment ${ }^{7}$ da presidente Dilma e na eleição do presidente Bolsonaro com a indicação de Paulo Guedes para ministro da economia. As crises atuais, os desencontros nas ações governamentais e os efeitos da pandemia na esfera social e econômica cada vez mais indicam a necessidade de novos pactos entre classes, atores e instituiçóes para conseguirmos superar a crise. Aqui mais uma vez, Jaguaribe nos parece interessante porque tal como nas análises do autor sobre o Brasil dos anos 1950 a 1970, por exemplo, o Brasil atual também requer de racionalidade e pactos entre atores, instituiçóes e classes, em outras palavras, a necessária articulação entre Estado e Mercado e a centralidade do planejamento na política econômica nos parece ainda ser uma questão de primeira grandeza no Brasil. 


\begin{abstract}
Notas
${ }^{1}$ Está pesquisa contou com apoio financeiro da Fundação Carlos Chagas Filho de Amparo à Pesquisa do Estado do rio de Janeiro - FAPERJ.

${ }^{2}$ No plano europeu, em particular, ainda se refere ao chamado período de ouro do capitalismo, ou os trinta anos gloriosos do capitalismo, onde a combinação de estratégia econômica de orientação keynesiana com a democracia representativa no âmbito do Estado vão caracterizar uma das experiências mais bem sucedidas de Estado de Bem Estar Social (Welfare State) que conseguiu alinhar crescimento econômico e desenvolvimento social, ou seja, crescer com equidade, distribuição de renda e estabilidade política.

${ }^{3}$ Cabe ressaltar que o conceito de subdesenvolvimento é forjado a partir da periferia do sistema capitalista e também da periferia da produção intelectual no intuito de caracterizar a condição histórica e os processos econômicos e sociais pelos quais os países Latino Americanos (principalmente), asiáticos e africanos estavam passando. Mas também não deixa de ser um conceito crítico ao estabelecer que desenvolvimento e subdesenvolvimento eram contemporâneos e não um anterior ao outro. Celso Furtado é um dos principais autores neste debate.

${ }^{4}$ Aqui utilizamos a versão publicada pela Contraponto e pelo Centro Internacional Celso Furtado em 2010

${ }^{5}$ Sobre o engajamento do ISEB na sua última fase, ver LOVATTO, 2017

${ }^{6}$ Duas outras formas são construídas pelo autor, o capitalismo de Estado e o socialismo desenvolvimentista. Esses seriam mais fáceis de implantar, porém mais difíceis de manter. Ao passo que o nacional capitalismo seria mais difícil de implantar, porém mais fácil de manter. Além do mais, ao passo que o nacional capitalismo seria democrático, o capitalismo de Estado e o socialismo desenvolvimentista seriam autoritários.

${ }^{7}$ Marcado por inúmeras controvérsias, inclusive sendo tratado por parte da literatura como um golpe em sua forma moderna, qual seja, a de ser realizado por meios dos próprios arranjos institucionais do Estado.
\end{abstract}

\section{Bibliografia}

ABREU, A. A. A ação política dos intelectuais do ISEB. In: NAVARRO, C. T. Intelectuais e política no Brasil: a experiência do ISEB. Rio de Janeiro: Editora Revan, 2005.

AGARWALA, A. N. \& SINGH, S. P. (org.). A economia do subdesenvolvimento. Rio de Janeiro: Contraponto: Centro Internacional Celso Furtado, 2010.

BIELSCHOWSKY, R. (org.). Cinquenta anos de pensamento na Cepal (vol 1 e vol 2). Rio de Janeiro: CEPAL, 2000a.

BIELSCHOWSKY, R. Pensamento econômico brasileiro: o ciclo ideológico do desenvolvimentismo. Rio de Janeiro: Contraponto, 200ob.

BOYER, R. Une théorie du capitalisme est-elle possible? Paris: Odile Jacob, 2004.

BLUMER, H. An appraisal of Thomas and Znaniecki'. s The Polish peasants in Europe and America (Critiques of research in the social sciences). Social Science Research Council: Bulletin: 44. Volume 1 de Critiques of research in the social sciences, 1939
BOTELHO, A. As viagens de Mario de Andrade à Amazônia entre raízes e rotas. Rev. Inst. Estud. Bras., São Paulo, n. 57, p. 15-50, dez., 2013

BRESSER-PEREIRA, L. C. Seis Interpretações sobre o Brasil. DADOS - Revista de Ciências Sociais, Rio de Janeiro, v. 25, n. 3، pp. 269-306, 1982

CASANOVA, P. G. Las categorías del desarrollo económico y la investigación em Ciencias Sociales. México: Instituto de Investigaciones Sociales, Universidad Nacional Autónoma de México, 1967

COSTA PINTO, L. La sociología del cambio y el cambio de la sociología. Buenos Aires: Eudeba, 1963

FERNANDES, F. Sociedade de classes e subdesenvolvimento. Rio de Janeiro, Zahar Editores, 1981

FURTADO, C. Criatividade e dependência na civilização industrial. Rio de Janeiro: Paz e Terra, 1978. 
FURTADO, C. Economia do desenvolvimento (curso ministrado na PUC-SP em 1975). Rio de Janeiro: Contraponto: Centro Internacional Celso Furtado, 2008.

FURTADO, C. Desenvolvimento e subdesenvolvimento. Rio de Janeiro: Contraponto: Centro Internacional Celso Furtado, 2009.

GERSCHENKRON, A. O atraso econômico em perspectiva histórica e outros ensaios. Rio de Janeiro: Contraponto: Centro Internacional Celso Furtado, 2015.

HAGEN, E. E. As origens do desenvolvimento. São Paulo: Editora Fórum, 1986.

IANNI, O. Estado e Planejamento Econômico no Brasil. RJ: Editora Civilização Brasileira, 1986.

IANNI, O. Tipos e mitos do pensamento brasileiro. Revista Sociologias, Porto Alegre, ano 4, n.7, janeiro-junho, 2002.

JAGUARIBE, H. A crise brasileira. Cadernos do Nosso Tempo, $\mathrm{n}^{\circ} 1$. Rio de Janeiro: IBESP, 1953.

. Situação política brasileira. Cadernos do Nosso Tempo, $\mathrm{n}^{\circ}$ 2. Rio de Janeiro: IBESP, 1954.

. Para uma política nacional de desenvolvimento. Cadernos do Nosso Tempo, $\mathrm{n}^{\circ} 5$. Rio de Janeiro: IBESP, 1956a.

O problema do desenvolvimento econômico e a burguesia nacional. São Paulo: Coleção Fórum Roberto Simonsen, 1956b.

. Condições institucionais ao desenvolvimento. Rio de Janeiro: ISEB, 1958.

. O nacionalismo na atualidade brasileira. Rio de Janeiro: ISEB, 1958b.

. Desenvolvimento econômico e desenvolvimento político. Rio de Janeiro: Paz e Terra, 1968.

"O ISEB e o desenvolvimento nacional" In: TOLEDO, C. N. Intelectuais e política no Brasil. A experiência do ISEB. Rio de Janeiro: Revan, 2005.

LAHUERTA, M. Intelectuais e resistência democrática: vida acadêmica, marxismo e política no Brasil. Cadernos AEL, v. 8, n. 14/15, 2001.
LEME, A. A. Desenvolvimento e sociologia: uma aproximação necessária. Revista Sociedade e Estado, Brasília, v. 30, n. 2, p. 495-527, ago. 2015.

LEME, A. A. \& LENK, W. Desenvolvimento e política: apontamentos em Fernando Henrique Cardoso e Hélio Jaguaribe. e-l@tina: Revista electrónica de estudios latinoamericanos, v. 13, n. 49, Buenos Aires, Oct.-Dic, 2014a.

LEME, A.A; BRASIL JR. A.S. Sociologia do Desenvolvimento e Pensamento Social no Brasil: proposta para uma agenda de pesquisa. Dossiê: pensamento social, desenvolvimento e desafios contemporâneos; dez. Crítica e Sociedade: revista de cultura política. v. 4, n. 2, 2014b

LEWIS, A. A teoria do desenvolvimento econômico. Editora: Zahar, 1960.

LEWIS, A. The theory of economic growth. The Economic Journal, v. 66, n. 264, pp. 694697, Dec. 1956

LIMA, N. T. \& BOTELHO, A. Malária como doença e perspectiva cultural nas viagens de Carlos Chagas e Mário de Andrade à Amazônia. Hist. cienc. Saúde-Manguinhos, Rio de Janeiro, v. 20, n. 3, p. 745-763, Sept. 2013.

LOVATTO, A. Pensamento Político Brasileiro no Último ISEB (1961-64). GT-31 - Teoria Política e Pensamento Político Brasileiro conflito, poder, legitimidade e Estado. 410. Encontro Anual da ANPOCS, 2017.

MARX, K. Manuscritos económico-filosóficos. São Paulo: Nova Cultural, (Coleção Os Pensadores), 1991.

MATOS MAR, José. La dominación de América Latina. Buenos Aires: Editorial Amorrortu, 1972.

MERTON, T. Ascenção para a verdade. RJ: Editora Itatiaia, 1958.

MYRDAL, K. G. O estado do futuro: o planejamento econômico nos estados de bem-estar e suas implicações internacionais. Rio de Janeiro: Zahar, 1962. 
MYRDAL, K. G. Teoria Econômica e Regiões Subdesenvolvidas. Rio de Janeiro: Editora Saga, 1957.

MYRDAL, K. G. Perspectivas de uma economia internacional. Rio de Janeiro: Editora Saga, 1967.

NURKSE, R. Problemas da Formação de Capital em Países Subdesenvolvidos (1952). Rio de Janeiro: Editora Civilização Brasileira, 1957.

NURSKE, R. Equilibrium and growth in the world economy. HABERLER, G. \& STERN, R. M. (Eds.). Harvard Economic Studies CXVIII. Cambridge (MA): Har- vard University Press, 1961.

OLIVEIRA, F. A economia brasileira: crítica à razão dualista. Rio de Janeiro. Vozes, 1988

PEÑA, F. C. Dependencia Y câmbios estructurales. México: Instituto de Investigaciones Economicas. Universidad Nacional Autonoma de Mexico, 1971.

PEREIRA, A. E. Intelectuais, política e cultura na formação do ISEB. In NAVARRO, C. T. Intelectuais e política no Brasil: a experiência do ISEB. Rio de Janeiro: Editora Revan, 2005.

PERROUX, F. Economia e sociedade. Editora: Duas Cidades, 1961.

PERROUX, F. A Economia do Século XX. Lisboa: Livraria Morais Editora. PERROUX, F. Nota Sobre o Conceito de "Pólo de Crescimento". In: PERROUX, F; FRIEDMANN, J \& TINBERGEN, J. A Planificação e os Pólos de Desenvolvimento. Porto: Edições Rés Limitada, 1967, pp. 5-26. 82 p
RODRÍGUEZ, O. O estruturalismo LatinoAmericano. Rio de Janeiro: Civilização Brasileira, 2009.

ROSTOW, W. W. The stages of economic growth. Economic History Review, ago, 1959.

ROSTOW, W. W. Etapas do desenvolvimento econômico (um manifesto não comunista). 5. ed. ampl. Rio de Janeiro: Zahar, 1974.

SUNKEL, O. \& PAZ, P. El Subdesarrollo Latinoamericano y La Teoría del Desarrollo. México: Siglo Veintiuno, 1970.

SUNKEL, O. \& PAZ, P. Um ensaio de interpretação do desenvolvimento latino-americano. Forum Editora, 1975.

TOLEDO, C. N. ISEB: Fábrica de Ideologias. São Paulo: Ática, 1982.

TOLEDO, C. N. (org). Intelectuais e política no Brasil. A experiência do ISEB. Rio de Janeiro: Revan, 2005.

TOURAINE. A. Palavra e Sangue: Política e Sociedade na América Latina. Tradução de Iraci D. Poleti. São Paulo: Editora da Universidade Estadual de Campinas, 1989

TOURAINE, A. Brasil em Desenvolvimento, v. 2. São Paulo: Civilização Brasileira, 2005

WEFFORT, F. Formação do pensamento político brasileiro: ideias e personagens. Editora Ática, 2006.

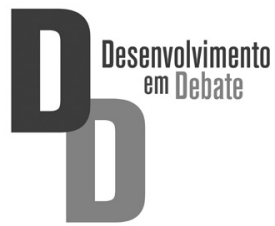

